\title{
Total edentulous prosthesis using hybrid restorations
}

\author{
Protezarea edentaţiei totale utilizând restaurări hibride
}

\begin{tabular}{|c|}
\hline $\begin{array}{l}\text { Alexandru Daniel Referendaru1,2, Horia Mihail Barbü }{ }^{2,3} \text {, } \\
\text { Raluca Monica Comăneanu }{ }^{3} \text {, Anca Iuliana Popescu }{ }^{3}\end{array}$ \\
\hline $\begin{array}{l}\text { 'Şcoala Doctorală - Domeniul Medicină Dentară, IOSUD „Titu Maiorescu“, Bucureşti, România } \\
\text { [2Clinica de Reabilitare Orală „Prof. Dr. Barbu“, Bucureşti, România } \\
\text { "3Facultatea de Medicină Dentară, Universitatea „Titu Maiorescu“, Bucureşti, România }\end{array}$ \\
\hline
\end{tabular}

\begin{abstract}
Purpose. The increasing frequency of using prosthetic restorations with implant aggregation confirms the great interest of patients in the application of modern dental therapies to restore the functions of the dento-maxillary apparatus, lost as a result of edentations.

Case presentation. Patient D.D., aged 63, approached our clinic for consultation and the establishment of a specialized treatment. At the clinical and radiological examination we found the presence of a total maxillary edentation and a Kennedy class I edentation with a change in the lower arch, with all the remaining teeth with indication of extraction. Following the consultation carried out together with the dentist, we proposed to the patient a treatment plan that involved bimaxillary prosthesis on implants.

Conclusions. Prosthetic restorations with implant aggregation offer patients with total edentations the possibility to recover the functions of the dento-maxillary apparatus at a higher level than traditional prostheses. Hybrid prosthesis with aggregation on zygomatic and pterygoid implants allows the reduction of the treatment duration and the decrease of the costs, in the conditions of maintaining a high therapeutic predictability.
\end{abstract}

Keywords: restorations with implant aggregation, total edentation, modern dental therapies

\section{REZUMAT}

Scop. Frecvenţa tot mai mare a utilizării restaurărilor protetice cu agregare implantară confirmă interesul crescut al pacienților faţă de aplicarea unor terapii dentare moderne pentru refacerea funcţiilor aparatului dento-maxilar pierdute ca urmare a edentaţiilor.

Prezentarea cazului. Pacientul D.D., în vârstă de 63 ani, s-a adresat clinicii noastre pentru consult şi instituirea unui tratament de specialitate. La examenul clinic și radiologic, am constatat prezenţa unei edentaţii totale maxilare şi a unei edentaţii clasa I Kennedy, cu o modificare la arcada inferioară, cu toţi dinţii restanţi cu indicaţie de extracţie. În urma consultului efectuat împreună cu medicul specialist în protetică dentară, am propus pacientului un plan de tratament care a implicat protezarea bimaxilară pe implanturi.

Concluzii. Restaurările protetice cu agregare implantară oferă pacienților cu edentații totale posibilitatea recuperării funcțiilor aparatului dento-maxilar la un nivel superior faţă de protezele tradiționale. Protezarea hibridă cu agregare pe implanturi zigomatice şi pterigoidiene permite reducerea duratei de tratament şi scăderea costurilor, în condiţiile menţinerii unei predictibilităţi terapeutice ridicate.

Cuvinte cheie: restaurări cu agregare implantară, edentație totală, terapii dentare moderne

\section{INTRODUCERE}

Scopul stomatologiei moderne este de a restabili sănătatea orală a pacienților într-un mod predictibil.

Restaurările cu agregare implantară prezintă faţă de protezele fixe convenţionale o serie de avantaje, precum:
- rată crescută de succes (la 10 ani, peste 97\%);

- risc redus de afectare odontală sau endodontică la dinţii vecini breşei edentate;

- menţinerea osului crestei edentate [1].

Încă din faza de planificare a tratamentului, pacientul trebuie foarte bine evaluat din punctul de vedere al stării de sănătate generală $[2,3]$, fiind cu- 
noscut faptul că unele afecţiuni contraindică permanent sau temporar efectuarea intervenţiilor de chirurgie orală. Evaluarea imagistică precisă (ortopantomogramă, CBCT) oferă informaţii necesare pentru buna desfăşurare a etapelor chirurgicale şi protetice [1] ale reabilitării orale complexe.

\section{CAZ CLINIC}

Pacientul D.D., hipertensiv, 63 ani, s-a prezentat în clinică pentru consult şi tratament de specialitate. La examenul clinic și radiologic, am constatat prezenţa unei edentaţii totale maxilare şi a unei edentaţii clasa I Kennedy, cu o modificare la arcada inferioară, cu toţi dinţii restanţi cu indicaţie de extracţie.

În urma consultului efectuat împreună cu medicul specialist în protetică dentară, am propus pacientului un plan de tratament care a implicat protezarea bimaxilară pe implanturi.
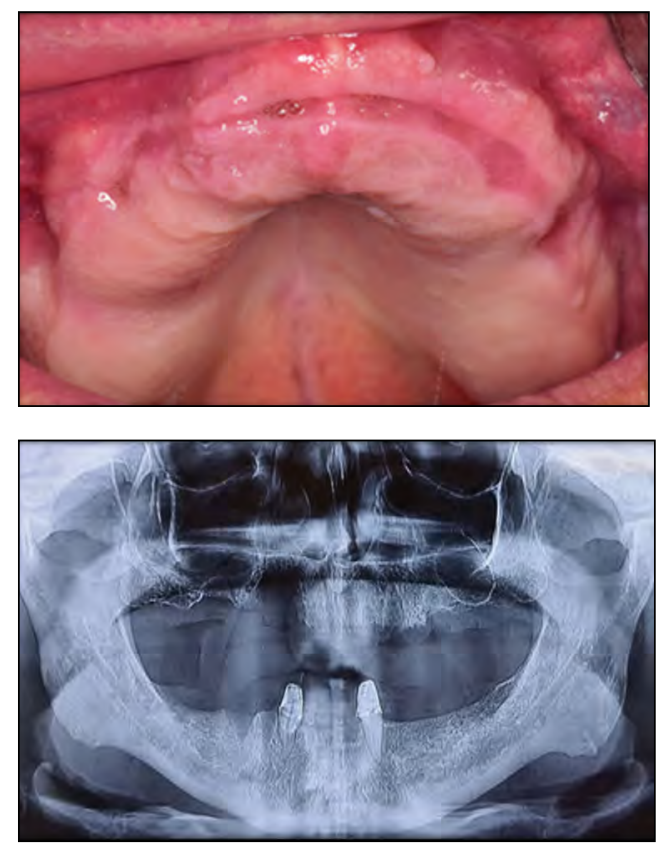

FIGURA 1. Situație clinică (a) şi radiologică (b) inițială

La maxilar s-a decis confecţionarea unei proteze hibride cu agregare prin înşurubare pe implanturi. Pentru a evita efectuarea sinus liftingului bilateral, s-au inserat la arcada superioară 6 implanturi pterigoidiene (în regiunile 17-13-21-23-25-27) şi un implant zigomatic (în regiunea 15) sub diferite unghiuri: $0^{\circ}-30^{\circ}-45^{\circ}$, în concordanţă cu resorbţia crestei edentate.

Implantul zigomatic s-a inserat după ce s-a practicat îndepărtarea corticalei vestibulare cu freze di- amantate speciale, urmată de decolarea şi elevarea membranei schneideriene cu chiuretele de sinus lifting, pentru a nu o efracţiona cu frezele utilizate ulterior la prepararea neoalveolei.

Pentru implanturile pterigoidiene, alveolele s-au realizat subdimensionat, din cauza densităţii osoase reduse de la acest nivel.

La arcada inferioară, au fost inserate fără înclinare 6 implanturi pterigoidiene în regiunile 36-3432-42-44-46, pe care s-a realizat o proteză hibridă cu agregare prin înşurubare.
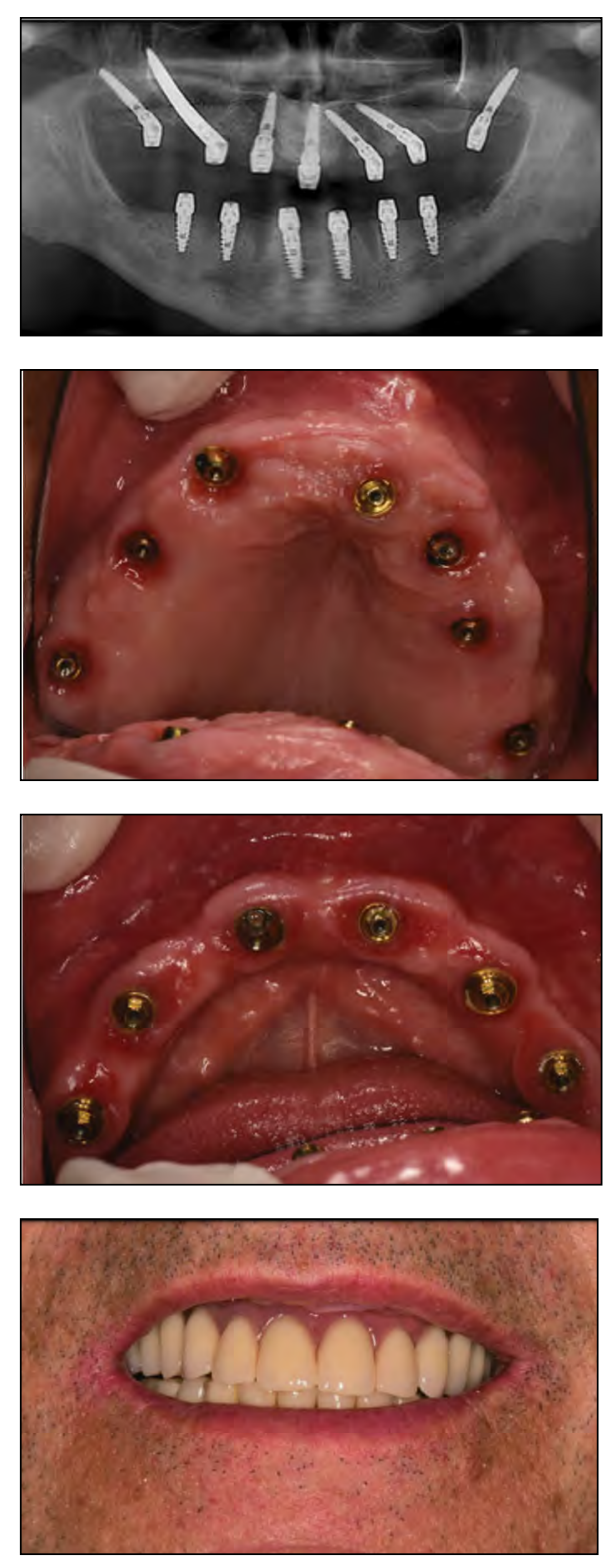

FIGURA 2. Imagini radiologice (a) şi clinice (b, c, d) din cursul tratamentului

\section{DISCUṬII}

Frecvenţa tot mai mare a utilizării restaurărilor protetice cu agregare implantară confirmă interesul 
crescut al pacienților faţă de aplicarea unor terapii dentare moderne pentru refacerea funcţiilor aparatului dento-maxilar pierdute ca urmare a edentaţiilor.

Pentru a evita practicarea intervenţiilor chirurgicale de augmentare a substratului osos deficitar [410], la pacienţii cu posibilităţi materiale limitate şi la care situaţia clinică permite, se pot insera implanturi pterigoidiene şi zigomatice [11-13], sub diferite unghiuri ce permit protezarea ulterioară în condiţii de siguranţă.

Într-un studiu efectuat de Davo în 2012, s-a raportat o rată de supraviețuire de $100 \%$ după 12 ani de urmărire la un lot de 27 pacienţi la care au fost inserate 65 de implanturi zigomatice [14].

O revizuire sistematică mai recentă raportează o rată de supraviețuire cumulată la 12 ani de 95,21\% pe baza a 68 de studii despre 4.556 de implanturi zigomatice inserate la 2.161 de pacienți și concluzionează că tehnica are o predictibilitate ridicată cu rezultate clinice bune [15].

Unul dintre cele mai importante avantaje al utilizării implanturilor pterigoidiene este eliminarea necesității de a efectua intervenții chirurgicale de elevare a sinusurilor maxilare sau grefe osoase, ceea ce permite scăderea morbidității și reducerea timpului de tratament, deoarece s-a dovedit că osteointegrarea implanturilor pterigoidiene poate apărea în numai 2-3 luni $[16,17]$.

\section{CONCLUZII}

Restaurările protetice cu agregare implantară oferă pacienților cu edentații totale posibilitatea recuperării funcțiilor aparatului dento-maxilar la un nivel superior faţă de protezele tradiționale.

Protezarea hibridă cu agregare pe implanturi zigomatice şi pterigoidiene permite reducerea duratei de tratament şi scăderea costurilor, în condiţiile menţinerii unei predictibilităţi terapeutice ridicate.

\section{Menţiune}

Toţi autorii au avut o contribuţie egală la publicarea acestui material.

Conflict of interest: none declared Financial support: none declared

\section{BIBLIOGRAFIE}

1. Gupta R, Weber KK. Dental Implants. In: StatPearls. Treasure Island (FL): StatPearls Publishing; 2020.

2. Diz P, Scully C, Sanz M. Dental implants in the medically compromised patient. J Dent. 2013;41(3):195-206.

3. Chanavaz M. Patient screening and medical evaluation for implant and preprosthetic surgery. J Oral Implantol. 1998;24(4):222-9.

4. Kang DW, Yun PY, Choi YH, Kim YK. Sinus bone graft and simultaneous vertical ridge augmentation: Case series study. Maxillofac Plast Reconstr Surg. 2019;41(1):36.

5. Scarano A, Lorusso F, Santos de Oliveira P, Kunjalukkal Padmanabhan S, Licciulli A. Hydroxyapatite Block Produced by Sponge Replica Method: Mechanical, Clinical and Histologic Observations. Materials (Basel). 2019;12(19):3079.

6. Joshi CP, D'Lima CB, Karde PA, Mamajiwala AS. Ridge augmentation using sticky bone: $A$ combination of human tooth allograft and autologous fibrin glue. J Indian Soc Periodontol. 2019;23(5):493-496.

7. Liu Y, Sun X, Yu J et al. Platelet-Rich Fibrin as a Bone Graft Material in Oral and Maxillofacial Bone Regeneration: Classification and Summary for Better Application. Biomed Res Int. 2019;2019:3295756.

8. Zhou Z, Wang Y, Meng W, Yang X, Dao J. Two-stage Closed Sinus Lift for Severe Bone Deficiency in the Posterior Maxilla Imrpoves Long-Term Clinical Outcomes. Nan Fang Yi Ke Da Xue Xue Bao. 2019 Jun 30;39(6):731-735.

9. Soardi CM, Soardi B, Wang HL. Crestal Window Sinus Lift and Its Long-Term Clinical Outcomes [published online ahead of print, 2020 Mar 19]. Int J Periodontics Restorative Dent. 2020.

10. Kempraj J, Sundaram SS, Doss GPT, Nakeeran KP, Raja VBKK. Maxillary Sinus Augmentation Using Xenograft and Choukroun's Platelet-Rich Fibrin as Grafting Material: A Radiological Study. J Maxillofac Oral Surg. 2020;19(2):263-268.

11. Graves SL. The pterygoid plate implant: A solution for restoring the posterior maxilla. Int J Periodontics Restorative Dent. 1994;14:51223.

12. Bahat O. Osseointegrated implants in the maxillary tuberosity: Report on 45 consecutive patients. Int J Oral Maxillofac Implants. 1992;7:459-67.

13. Balaji VR, Lambodharan R, Manikandan D, Deenadayalan $S$. Pterygoid Implant for Atrophic Posterior Maxilla. J Pharm Bioallied Sci. 2017;9(Suppl 1):S261-S263.

14. Davo R. Sinus reactions to zygomatic implants. In: Aparicio C., editor. Zygomatic Implants: The Anatomy Guided Approach. Quintessence Publishing Co., Inc.; Berlin, Germany: 2012. pp. 59-76.

15. Chrcanovic BR, Albrektsson T, Wennerberg A. Survival and Complications of Zygomatic Implants: An Updated Systematic Review. J Oral Maxillofac Surg. 2016;74:1949-1964.

16. Tulasne JF. Osseointegrated fixtures in the pterygoid region. In Advanced Osseointegration Surgery: Applications in the Maxillofacial Region (eds. Worthington P, Branemark PI), Chicago: Quintessence, 1992, pp. 182-188.

17. Balshi TJ, Wolfinger GJ, Balshi SF. Analysis of 356 pterygomaxillary implants in edentulous arches for fixed prosthesis anchorage. Int $\mathrm{J}$ Oral Maxillofac Implants. 1999;14:398-406. 